\title{
Erratum to: Maricoccus atlantica gen. nov. sp. nov., isolated from deep sea sediment of the Atlantic Ocean
}

\author{
Guizhen Li • Qiliang Lai · Xiupian Liu • \\ Fengqin Sun • Yaping Du • Guangyu Li • \\ Zongze Shao
}

Published online: 9 January 2014

(C) Springer Science+Business Media Dordrecht 2014

\section{Erratum to: Antonie van Leeuwenhoek (2013) 104:1073-1081 DOI 10.1007/s10482-013-0029-8}

Subsequent to the publication of the above paper it has been brought to our attention that the name proposed in the paper cannot be validated as it is a later homonym of the isopod genus name Maricoccus Poore, 1994. We here propose a new name for the taxon represented by strain $22 \mathrm{II}-\mathrm{S} 10 \mathrm{r} 2^{\mathrm{T}}$ :

\section{Description of Oceanococcus gen. nov.}

Oceanococcus [O.ce.a.no.coc'cus. Gr. n. okeanos, ocean; N.L. masc. n. coccus (from Gr. masc. n.

The online version of the original article can be found under doi:10.1007/s10482-013-0029-8.

G. Li · Q. Lai · X. Liu · F. Sun · Y. Du ·

G. Li $\cdot$ Z. Shao $(\bowtie)$

State Key Laboratory Breeding Base of Marine Genetic Resources; Key Laboratory of Marine Genetic Resources, Third Institute of Oceanography, SOA; Key Laboratory of Marine Genetic Resources of Fujian Province,

Xiamen 361005, China

e-mail: shaozz@163.com

G. Li · Q. Lai

Life Science College, Xiamen University,

Xiamen 361005, China kokkos), a grain or berry; N.L. masc. n. Oceanococcus, a coccus from the ocean].

The description of the genus is as given for Maricoccus in Li et al. (2013) Antonie van Leeuwenhoek 104: 1073-1081.

The type species is Oceanococcus atlanticus.

\section{Description of Oceanococcus atlanticus}

Oceanococcus atlanticus (at.lan'ti.cus. L. masc. adj. atlanticus Atlantic, from the Atlantic Ocean).

The description of the species is as given for Maricoccus atlantica in Li et al. (2013) Antonie van Leeuwenhoek 104:1073-1081. The type strain is 22IIS10r2 ${ }^{\mathrm{T}}\left(=\right.$ CGMCC NO.1.12317 ${ }^{\mathrm{T}}=$ LMG $27155^{\mathrm{T}}=$ MCCC $1 \mathrm{~A} 09384^{\mathrm{T}}$ ). 